\title{
Chitosan particles agglomerated scaffolds for cartilage and osteochondral tissue engineering approaches with adipose tissue derived stem cells
}

\author{
P. B. MAlafAyA ${ }^{1, *}$, A. J. Pedro ${ }^{1}$, A. Peterbauer ${ }^{2,3}$, C. GABRIEL ${ }^{3}$, H. REDL $^{2}$, \\ R. L. REIS ${ }^{1}$ \\ ${ }^{1} 3 B$ 's Research Group-Biomaterials, Biomimetics and Biodegradables, Dept. Polymer \\ Eng., Univ. of Minho, Campus de Gualtar, 4710-057 Braga, Portugal \\ E-mail: pmalafaya@dep.uminho.pt \\ ${ }^{2}$ Ludwig Boltzmann Institute for Experimental and Clinical Traumatology, \\ Donaueschingenstr. 13, A-1200 Vienna, Austria \\ ${ }^{3}$ Red Cross Transfusion Service for Upper Austria, Blumauerstr. 3-5, A-4020 Linz, Austria
}

It is well accepted that natural tissue regeneration is unlikely to occur if the cells are not supplied with an extracellular matrix (ECM) substitute. With this goal, several different methodologies have been used to produce a variety of 3D scaffolds as artificial ECM substitutes suitable for bone and cartilage tissue engineering. Furthermore, osteochondral tissue engineering presents new challenges since the combination of scaffolding and co-culture requirements from both bone and cartilage applications is required in order to achieve a successful osteochondral construct.

In this paper, an innovative processing route based on a chitosan particles aggregation methodology for the production of cartilage and osteochondral tissue engineering scaffolds is reported. An extensive characterization is presented including a morphological evaluation using Micro-Computed Tomography $(\mu \mathrm{CT})$ and 3D virtual models built with an image processing software. Mechanical and water uptake characterizations were also carried out, evidencing the potential of the developed scaffolds for the proposed applications. Cytotoxicity tests show that the developed chitosan particles agglomerated scaffolds do not exert toxic effects on cells. Furthermore, osteochondral bilayered scaffolds could also be developed. Preliminary seeding of mesenchymal stem cells isolated from human adipose tissue was performed aiming at developing solutions for chondrogenic and osteogenic differentiation for osteochondral tissue engineering applications.

(c) 2005 Springer Science + Business Media, Inc.

\section{Introduction}

Tissue engineering has developed into a multidisciplinary field using both the state of the art and breakthrough research of several different areas. It uses biological, chemical and materials engineering principles towards the repair, restoration or regeneration of living tissues combining biomaterials, cells and biologically active factors. This now well accepted concept leads to the basis of one of the three key issues in tissue engineering which is clearly the scaffolding that should provide an ideal site for cell attachment and proliferation leading to further tissue regeneration. The extracellular matrix (ECM) that surrounds cells in the body not only physically supports cells but also regulates their proliferation and differentiation. Conse- quently scaffolds need to be developed for sustaining in-vitro tissue reconstruction as well as for in-vivo cellmediated tissue regeneration. It is almost impossible to repair tissue defects if the cells are not supplied with such kind of an ECM substitute.

Bearing this in mind, several different methodologies have been used to produce a variety of three dimensional synthetic or naturally based scaffolds suitable for tissue engineering applications. Researchers have been using, for instance, injection moulding with blowing agents [1], solvent casting and salt leaching techniques [2] or the latter combined with compression moulding [3] or gas foaming $[4,5]$. In the salt leaching technique, the pre-incorporated salt in the polymeric matrix is dissolved creating the pores. Fibre bonding [6] has 
also been used to produce successfully fibre meshed 3D structures with high interconnectivity. Other techniques such as freeze-drying [7-9] and rapid prototyping technologies [10-12] have also been used to produce interesting scaffolds. Nevertheless, further research on the scaffold design is still needed because the chemical nature and structure of the 3D constructs significantly affect the success of tissue engineering approaches both in-vitro and in-vivo. Moreover, an optimal scaffold has not been identified yet.

Towards this goal, an innovative methodology is being developed in several groups, based on the agglomeration of prefabricated microspheres. The technique is generally based on the random packing of microspheres with further aggregation by physical or thermal means to create a three dimensional porous structure. This technique is being used to construct scaffolds directly [13] or it can be proposed to be used indirectly by producing a negative structure which will serve as a reverse template to obtain the scaffolds.

The research group of C.T. Laurencin [13-15] have been applying this technique for the development of poly(lactide-co-glycolide) (PLAGA) microspheresbased matrices for bone repair. The researchers have tried different approaches by developing sintered microspheres based matrices $[13,14]$ or gel microspheres matrices [15]. Composite microspheres containing hydroxyapatite were also used for the fabrication of polymer-ceramics 3D matrices for bone applications [16]. In the case of sintered microspheres matrices, the microspheres are first obtained by a solvent evaporation technique. The 3D structures are then further processed by heating the pre-fabricated PLAGA microspheres above the glass transition temperature. The polymer chains are activated to interlink with neighbouring polymer chains and thus form contacts between neighbouring microspheres [15]. In the gel microspheres matrix methodology, the PLAGA gel microspheres are obtained by emulsion with poly(vinyl alcohol) (PVA). The following agglomeration is based on a multiple step production that includes air-drying, freeze-drying, rehydration with salt leaching and freeze-drying again. In general, microsphere based matrices show very interesting properties for a possible application in bone repair.

Another strategy that uses microspheres includes their embedding in a hydrogel matrix [17-19]. In that approach, the goal of incorporation of previously produced microspheres is to encapsulate either cells [20] or biologically active factors for either favouring the cell attachment and proliferation behaviour [18, 21-23] or to enhance the vascularization [24].

Several million people worldwide suffer from severe joint pain and related dysfunction, such as loss of motion as a result of injury or osteoarthritis [25-28]. In particular, loss of function of the knees can severely reduce mobility and thus the patient's quality of life [29]. The biological basis of joint problems is the deterioration of articular cartilage which covers the bone at the joint surface [30]. Current treatments most widely used are based on autologous strategies such as mosaicplasty [31]. Abrasion arthroscopy, subchondral bone drilling and microfracture typically result in fibrocartilage filling the defect site [28]. Allogenic transplantation of osteochondral grafts has had clinical success, but its supply is limited and has a risk of infection or even rejection [26, 28]. Therefore, besides bone and cartilage tissue engineering approaches, a combination of both as osteochondral constructs is needed in clinical practice.

To create constructs with more favourable integrative properties several researchers are exploring the development of tissue engineered osteochondral composite constructs [26, 27, 32, 33]. However, osteochondral tissue engineering presents new interesting challenges because the combination of scaffolding and co-culture requirements from both bone and cartilage applications in an efficient way is required to achieve a successful osteochondral approach.

A few approaches have been proposed based on the development of bilayered 3D materials [25, 26, 32-35]. Osteochondral scaffolds based on collagen gels and calcium phosphate ceramics were proposed by Tagushi et al. [33]. The processing methodology consists of the formation of a calcium phosphate gradient into cartilage-like matrices containing type II collagen using a modified alternate soaking process. It was shown that, after a number of soaking cycles, calcium phosphate crystals were gradiently formed from the top to the middle of gels [33].

A very interesting work was presented by Sherwood et al. [26] in 2002 where a three-dimensional printing process was used to build a one-piece bilayered osteochondral scaffold. The upper, cartilage region was $90 \%$ porous and composed of D,L-PLGA/L-PLA, with macroscopic staggered channels to facilitate homogenous cell seeding. The lower, cloverleaf-shaped bone portion was $55 \%$ porous and consisted of a $\mathrm{L}-$ PLGA/TCP composite, designed to maximize bone ingrowth while maintaining critical mechanical properties [26].

A different approach was used by $\mathrm{Lu}$ et al. $[25,34$, 35]. They based their studies on chondrocyte encapsulation in agarose hydrogels for the cartilage component, and composites microspheres (PLAGA and Bioactive Glass ${ }^{\circledR}$ ) prepared by a water-oil-water emulsion and further sintered to produce the 3D scaffolds for the bone component. These studies showed that chondrocytes maintained their phenotype and developed a functional extracellular matrix. In addition, the osteochondral construct was found to be capable to simultaneously support the growth of multiple matrix zones. Recently, this research group has also presented a multi-phased composite scaffold for soft tissue-to-bone interface [34] using 3 different phases composed by PLAGA woven mesh, PLAGA microspheres and PLAGA-Bioactive Glass ${ }^{\circledR}$ microspheres. Studies were undertaken with osteoblasts and fibroblasts to evaluate the potential of supporting multiple cell types and the scaffold was used as a model system to regenerate soft tissue to bone interface.

In the present paper, a new processing route based on chitosan particles aggregation is described for the production of cartilage and osteochondral tissue 
engineering scaffolds. The described method uses previously prepared chitosan-based particles. For the osteochondral approach, bilayered scaffolds were developed in order to achieve an improved integrative bone and cartilage interface needed for these applications. Preliminary cell tests were performed by seeding mesenchymal stem cells isolated from human adipose tissue on the scaffolds and trying to promote them both in chondrogenic and osteogenic differentiation. This is a prerequisite for cartilage and osteochondral tissue engineering applications.

\section{Materials and methods}

\subsection{Scaffolds production}

Chitosan (from Sigma-Aldrich, medium molecular weight and $87.8 \%$ of deacetylation degree) was grinded and dissolved overnight in acetic acid ( $1 \% \mathrm{vv})$ to obtain a chitosan solution ( $2 \% \mathrm{wt}$ ). Unless otherwise stated, all chemicals were bought from Sigma-Aldrich and used as received. In composite particles production for the osteochondral bilayered scaffolds, $20 \%$ wt of nonsintered hydroxylapatite (HA) (CAM Implants, UK) with an average particle size of $6 \mu \mathrm{m}$ [36] was homogeneously dispersed in the chitosan solution. After complete dissolution and filtration, the prepared solutions were extruded trough a syringe at constant rate $(10 \mathrm{ml} / \mathrm{h})$ to form chitosan droplets into a $\mathrm{NaOH}$ (1 M) precipitation bath where particles with regular diameter were formed. The chitosan particles were left overnight in the precipitation bath and then repeatedly washed with distilled water. For the production of the bilayered scaffolds, the composite particles were submitted to a crosslinking reaction with glutaraldehyde. Further information on this can be found elsewhere $[37,38]$. The particles were subsequently pressed into moulds and left to dry in an oven at $50{ }^{\circ} \mathrm{C}$ for 3 days. Cylinder shaped scaffolds with $8 \mathrm{~mm}$ height and $5 \mathrm{~mm}$ in diameter were obtained. A schematic representation of the used methodologies is shown in Fig. 1.

\subsection{Scaffolds characterization}

The scaffolds morphology was analyzed by Scanning Electron Microscopy (SEM) in a Leica-Cambridge S-360 (Leica-Cambridge, UK) microscope equipped with V03.02A software. Micro-Computed Tomography $(\mu-\mathrm{CT})$ evaluation of the scaffolds was carried out using a Scanco 20 equipment (Scanco Medicals, Switzerland). X-ray scans were performed in high resolution mode $(9 \mu \mathrm{m})$ and 240 slices of the scaffolds were obtained. The 2-D histomorphometric analysis of the scaffolds was performed using a threshold 51 to identify the polymeric phase in order to determine the mean porosity as well as the porosity distribution along the scaffold (from 0 to $2000 \mu \mathrm{m}$ ). Furthermore, with the $\mu$-CT data import and MIMICS ${ }^{\circledR}$ (Materialise Interactive Medical Image Control System) image processing software (Materialise, Belgium), it was possible to build $3 \mathrm{D}$ virtual models representing the morphological structures of the scaffolds.

The mechanical properties of the developed scaffolds were tested on a compressive solicitation mode in an Instron Universal Mechanical Testing machine in a controlled environment $\left(23^{\circ} \mathrm{C} / 55 \% \mathrm{RH}\right)$. The cross-head speed used was $2 \mathrm{~mm} / \mathrm{min}$.

The hydration behaviour was assessed in media with different $\mathrm{pH}(5,7.4$ (physiological $\mathrm{pH})$ and 9) in order to study the potential responsive behaviour of the developed systems. The assays were performed at physiological temperature $\left(37^{\circ} \pm 1^{\circ} \mathrm{C}\right)$ for predetermined immersion periods up to 14 days. The swelling profile was characterized using the following equation:

$$
\% \text { Hydration degree }=\left[\left(W_{\mathrm{w}}-W_{\mathrm{i}}\right) / W_{\mathrm{i}}\right] \times 100
$$

where $W_{i}$ is the initial weight and $W_{w}$ is the wet weight at determined test period.

\subsection{In-vitro biological testing}

The cytotoxicity of the material was assessed by evaluating cellular viability using MTS assay (3-(4,5-dimethylthiazol-2-yl)-5-(3-carboxylmethoxyphenyl)-2(4-sulfophenyl)-2H tetrazolium) $\quad$ (Cell Titer $96^{\circledR}$

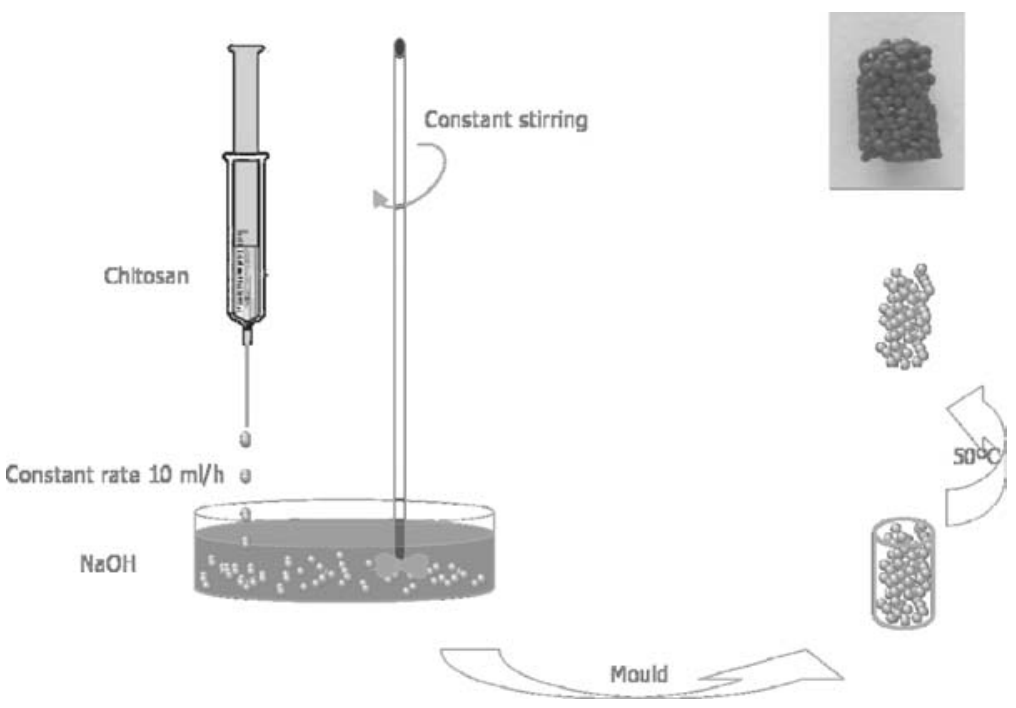

Figure 1 Schematic representation of the chitosan precipitation and particle aggregation methodologies. 
AQueous Solution Cell Proliferation Assay, G3580, Promega, USA). For this purpose, materials were incubated in culture medium for $24 \mathrm{~h}$ at $37^{\circ} \mathrm{C}$ with constant shaking. Latex was also incubated as a positive control. Cultured cells (L929 fibroblasts cell line) were plated $(200 \mu \mathrm{l} /$ well $)$ into 96 -well micrometer plates at $6.6 \times 10^{4}$ cells/well. The plates were incubated for $24 \mathrm{~h}$ at $37^{\circ} \mathrm{C}$ in a humidified atmosphere of $5 \%$ $\mathrm{CO}_{2}$ in air. After that, the medium was replaced by the previously prepared material extracts, using culture medium as a negative control. After a $72 \mathrm{~h}$ incubation, the cell culture was treated with MTS (in medium without phenol red) and incubated for further $3 \mathrm{~h}$ at $37^{\circ} \mathrm{C}$ in a humidified atmosphere of $5 \%$ of $\mathrm{CO}_{2}$ in air. At this stage, culture medium with MTS was transferred to new wells. The optical density (OD) which is directly proportional to the cellular activity (it reflects the mitochondrial activity) was read on a multiwell microplate reader (Synergy HT, Bio-Tek Instruments) at $490 \mathrm{~nm}$.

For the preliminary osteogenic and chondrogenic differentiation studies the scaffolds were seeded with mesenchymal stem cells (MSC) isolated from adipose tissue derived from liposuction procedures as previously described [39]. Briefly, the liposuction material was washed 3 times with phosphate buffered saline (PBS purchased from PAA, Austria) to remove most of the blood and tumescence solution. Afterwards the tissue was digested in PBS buffered with $25 \mathrm{mM}$ Hepes (PAA, Austria) containing $1.5 \mathrm{mg} / \mathrm{mL}$ collagenase (Biochrom, Germany) and $20 \mathrm{mg} / \mathrm{mL}$ bovine serum albumine (PAA, Austria) at $37^{\circ} \mathrm{C}$ under vigorous shaking for $1 \mathrm{~h}$. To eliminate red blood cells the isolated fraction was incubated with erythrocyte lysis buffer consisting of $154 \mathrm{mM} \mathrm{NH}_{4} \mathrm{Cl}, 10 \mathrm{mM} \mathrm{KHCO}_{3}$ and 0.1 $\mathrm{mM}$ EDTA for $10 \mathrm{~min}$ at $37^{\circ} \mathrm{C}$. After several washing and centrifugation steps the cells were filtered through a $100 \mu \mathrm{m}$ filter and cultured in DMEM/Ham'sF12 (1:1), $10 \%$ FCS, 2 mM L-glutamine, $100 \mathrm{U} / \mathrm{mL}$ penicillin and $100 \mu \mathrm{g} / \mathrm{mL}$ streptomycin at $37^{\circ} \mathrm{C}$ and $5 \% \mathrm{CO}_{2}$ in a water-saturated atmosphere. All cell culture reagents were purchased from PAA, Austria if not otherwise stated. Subculturing was performed before the cells reached confluence. Cells from passages 2 to 4 were used for the cell seeding experiments.

For this purpose, $5 \times 10^{5}$ cells were seeded onto each scaffold which were then cultured in control, osteogenic and chondrogenic medium, respectively. Osteogenic medium consisted of DMEM (1 g/L glucose), $10 \%$ FCS, 2 mM L-glutamine, $100 \mathrm{U} / \mathrm{mL}$ penicillin and $100 \mu \mathrm{g} / \mathrm{mL}$ streptomycin as well as $0.1 \mu \mathrm{M}$ dexamethasone (Sigma, Austria), $50 \mu \mathrm{M}$ ascorbate-2-phosphate (Fluka, Switzerland), $10 \mathrm{mM} \beta$ glycerophosphate (Sigma, Austria) and $10 \mathrm{nM} 1 \alpha, 25$ dihydroxyvitamin D3 (Fluka, Switzerland). Chondrogenic medium was comprised of DMEM (1 g/L glucose), $10 \%$ FCS, 2 mM L-glutamine, $100 \mathrm{U} / \mathrm{mL}$ penicillin and $100 \mu \mathrm{g} / \mathrm{mL}$ streptomycin as well as $0.1 \mu \mathrm{M}$ dexamethasone, $0.15 \mu \mathrm{M}$ ascorbate-2-phosphate, $1 \%$ insulin-transferrin-selenium supplement $(100 \times$, Invitrogen, Austria), $40 \mu \mathrm{M}$ L-proline (Sigma, Austria) and $10 \mathrm{ng} / \mathrm{ml}$ TGF- $\beta 1$ (PromoKine, Germany). After 2 weeks of incubation samples were prepared for SEM observation by washing the seeded scaffolds 3 times in pre-warmed PBS, fixing them in $2.5 \%$ glutaraldehyde at $4{ }^{\circ} \mathrm{C}$ for $30 \mathrm{~min}$ and washing them again 2 times with PBS. Then the samples were dehydrated in increasing concentrations of ethanol (50, 70, 90 and 100\%), each step lasting $30 \mathrm{~min}$. After air-drying the samples were incubated two times for $15 \mathrm{~min}$ in hexamethyldisilazane (Sigma, Austria).

The supernatant was harvested on day 7 and 14 for ALP activity determination using previously established protocols. In brief, 3 volumes of substrate solution consisting of $1 \mathrm{M}$ diethanolamine-hydrochloric acid buffer with $0.2 \%$ p-nitrophenylphosphate at $\mathrm{pH} 9.8$ were thoroughly mixed with the culture supernatant. After 45 to $60 \mathrm{~min}$ incubation at $37^{\circ} \mathrm{C} 4$ volumes of $2 \mathrm{M} \mathrm{NaOH}$ and $0.2 \mathrm{mM}$ EDTA were added to stop the enzymatic reaction. Immediately, the samples as well as serial dilutions of the standard p-nitrophenol ranging from 0 to $20 \mathrm{mmoL} / \mathrm{L}$ were measured in triplicate in a microplate reader (Amersham Biosciences, UK) at $405 \mathrm{~nm}$. Concentrations were calculated using a 4parameter fit curve. All reagents used for the ALP assay were purchased from Sigma, Austria.

Additionally, seeded wells without scaffolds were also incubated for 2 weeks with control, osteogenic and chondrogenic medium, respectively and stained with Von Kossa or Alcian Blue to detect osteogenic and chondrogenic differentiation in a 2D environment. For Von Kossa staining, the cells were fixed for $30 \mathrm{~min}$ with $10 \%$ neutral-buffered formalin. After rinsing with distilled water cells were overlaid with $5 \%$ silver nitrate for $30 \mathrm{~min}$. Staining was developed with $5 \%$ sodium carbonate in $25 \%$ neutral-buffered formalin and fixed by a 5 min incubation with $5 \%$ sodium thiosulphate. For Alcian Blue staining cells were rinsed with PBS and stained for $30 \mathrm{~min}$ at room temperature with $1 \%$ Alcian Blue in 3\% acetic acid at pH 2.5.

\section{Results and discussion}

\subsection{Scaffolds morphological and mechanical characterization}

Using the particle aggregation method, it was possible to obtain chitosan-based scaffolds with very interesting properties. The obtained chitosan particles are characterized by a smooth surface and uniform spherical shape with a mean diameter of $500-800 \mu \mathrm{m}$ confirmed by SEM microphotographs (Fig. 2(A)). After press-fitting into specific moulds and drying, chitosan scaffolds could be obtained with a mean pore diameter ranging from 100 to $400 \mu \mathrm{m}$ with a typical pore morphology shown in Fig. 2(B). However, the overall random packing of the chitosan particles into the $3 \mathrm{D}$ scaffold structures shown in the cross-section (Fig. 2(C)) clearly influenced the nature of the pores.

Fig. 2(C) shows the interconnectivity and threedimensional structure of the developed chitosan scaffolds. The bonding of the chitosan particles was achieved due to the bioadhesive character of the chitosan polymer that resulted in the union of adjacent particles at their contact points to form the chi- 

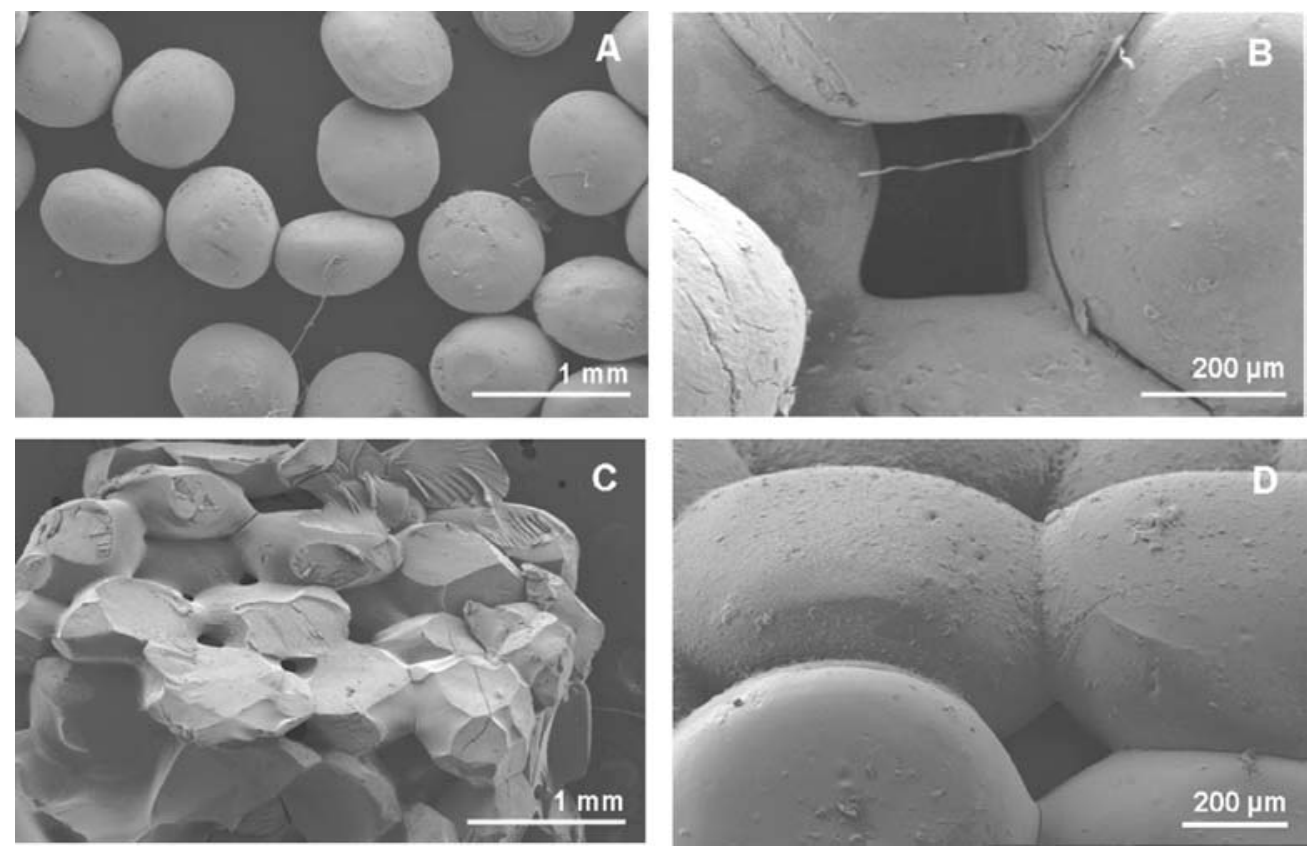

Figure 2 SEM micrographs of chitosan particles obtained by precipitation method (A); pore morphology in the chitosan scaffolds (B); cross-section of chitosan scaffolds obtained by the particle aggregation method (C); and interface between the chitosan particles after production of the scaffolds (D).

tosan porous matrices (Fig. 2(D)). The scaffold's crosssections (Fig. 2(C)) indicate the bonding areas by the flat planes on the particle surfaces. This chitosan particle bonding leads to a very stable interface between the particles which assure the mechanical integrity of the developed scaffolds. Concerning the compressive properties, scaffolds have shown a very good mechanical behaviour compared to the typical mechanical properties obtained for chitosan based porous materials. For the polymeric scaffolds, a high compressive modulus of $132 \pm 7 \mathrm{MPa}$ was obtained. Furthermore, it is important to keep in mind that the mechanical properties may be further increased when the scaffolds are crosslinked or a ceramic filler is incorporated.

SEM of relevant cross-sections (Fig. 2(C)) and $\mu$-CT analysis confirmed the formation of pores in the bulk of chitosan porous materials evidencing the scaffolds interconnectivity. The 2D histomorphometric analysis allowed for the characterization of the degree of porosity and pore distribution throughout the developed scaffolds as presented in Fig. 3. The developed scaffolds presented a mean porosity of about $30 \%$ (well distributed throughout the scaffold). In spite of the fact that many researchers are looking for scaffolds with much higher pore volumes, there is a compromise between the porosity and mechanical properties. In fact, for particles/microspheres agglomerated scaffolds it has been demonstrated that interconnected structures with a pore volume of at least $30 \%$ and a pore size of at least 100 $\mu \mathrm{m}$ are appropriate for cell ingrowth [13-15]. The main issue seems to be to assure a proper interconnectivity.

MIMICS $^{\circledR}$ (Materialise Interactive Medical Image Control System) is an image processing software and, in spite of being designed as an interface software for CT/MRI data and rapid prototyping machines, it can be very useful for the morphological characterization of scaffolds. MIMICS ${ }^{\circledR}$ enables $\mu$-CT data import and

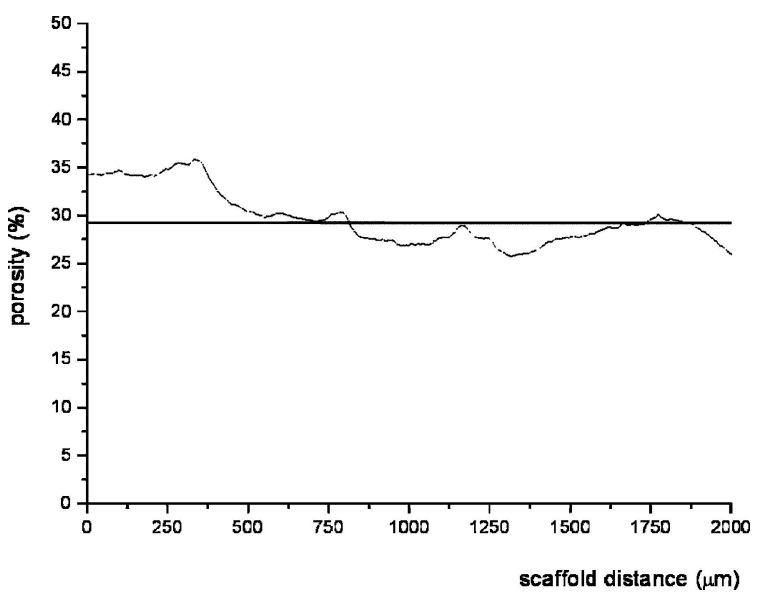

Figure 3 2D histomorphometric analysis of mean porosity (-) and pore distribution throughout the developed scaffolds.

with the segmentation, thresholding and visualization tools allows for the construction of accurate $3 \mathrm{D}$ virtual models of the developed scaffolds as shown in Fig. 4.

\subsection{Water uptake behaviour at different ph}

Concerning the water uptake, we observed a $\mathrm{pH}$ dependent behaviour of the developed scaffolds. In general, the degree of swelling of chitosan based materials is very high at $\mathrm{pH} 5$ compared to $\mathrm{pH} 7.4$ and 9 . This is due to the inherent hydrophobicity of chitosan dominating at high $\mathrm{pH}$ values. In polymeric scaffolds, a hydration equilibrium of $160-175 \%$ (depending on the $\mathrm{pH}$ of the medium) was reached after 8 days of immersion in different aqueous media as shown in Fig. 5. The swelling degree curve at $\mathrm{pH} 5$ begins to decline after day 3 , showing that the dissolution tendency exceeds the swelling degree (Fig. 5). This may be due to the protonation of the $\mathrm{NH}_{2}$ groups in the acidic medium. 

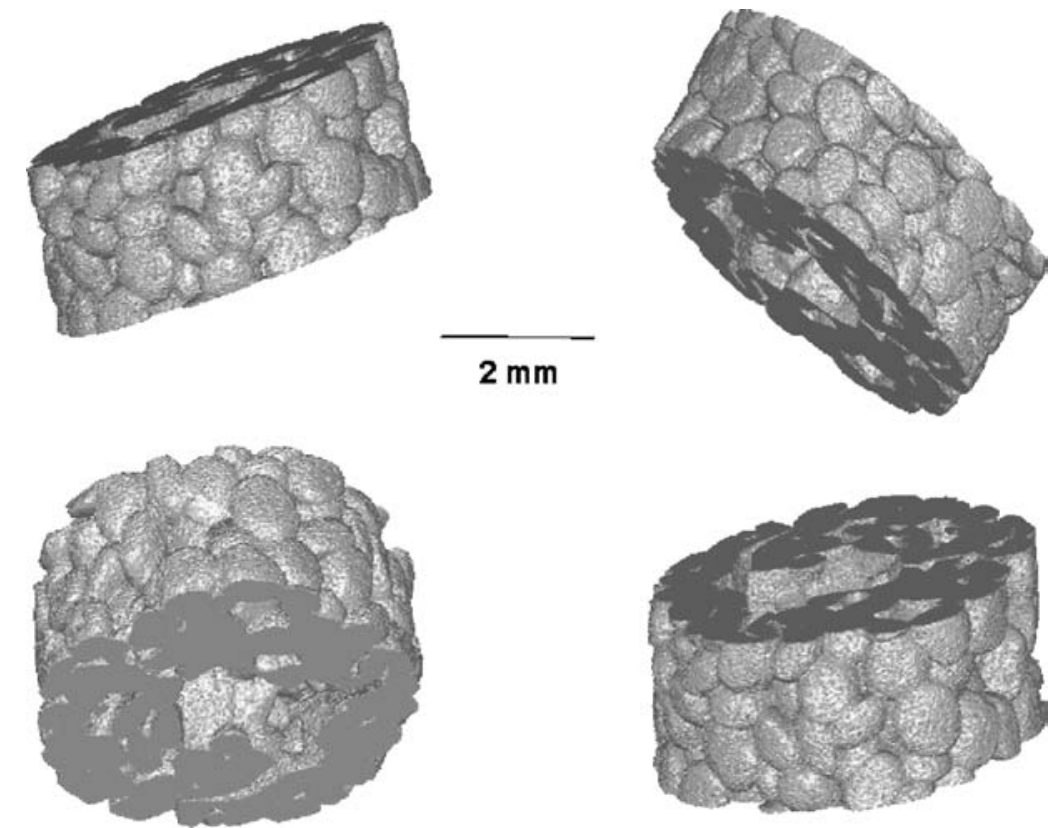

Figure 4 Different perspectives of 3D virtual models of the developed chitosan scaffolds produced by particle aggregation.

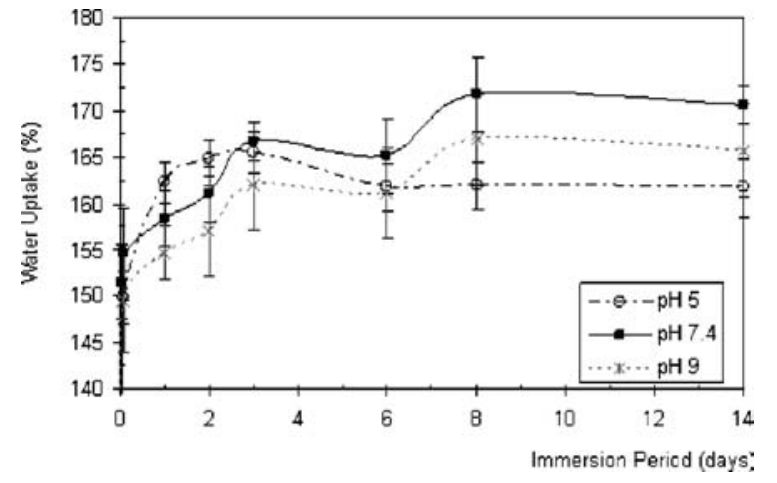

Figure 5 Water uptake behaviour of the chitosan porous scaffolds at different $\mathrm{pH}$.

However, and if desirable, this behaviour can be controlled by means of a crosslinking reaction where the dissolution is prevented by the reaction of the reactive $\mathrm{NH}_{2}$ groups with glutaraldehyde. This $\mathrm{pH}$ dependent behaviour will be very useful in a scaffold that should also exhibit controlled release of a desired biologically active agent at the implantation site, especially when considering the decrease of $\mathrm{pH}$ that is observed in-vivo due to the inflammatory response. Therefore, it might be very useful that the main mechanism which controls the release observed for chitosan based materials is their respective water uptake behaviour.

\subsection{Cytotoxicity tests}

MTS tests were performed in order to assess the potential cytotoxicity of the developed scaffolds. It was verified that extracts from the chitosan based scaffolds shown did not affect the cellular viability, since a similar cellular viability was obtained in the controls (culture medium). The MTS results are plotted in Fig. 6.

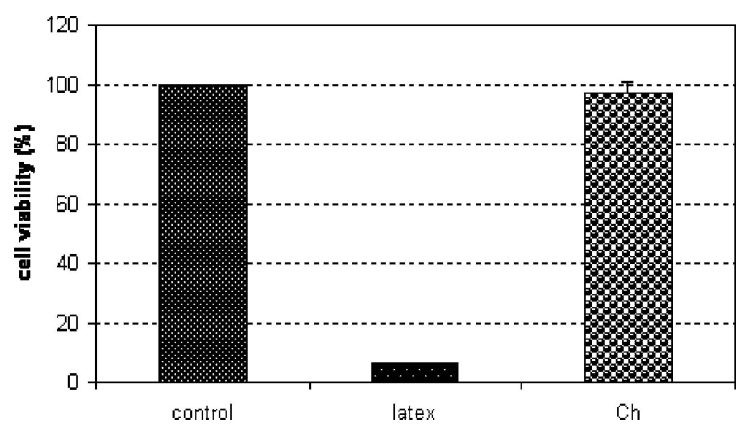

Figure 6 Cytotoxicity of the developed chitosan (Ch) scaffolds evaluated by MTS assay of $6.6 \times 10^{4}$ cells incubated with extracts of the scaffolds.

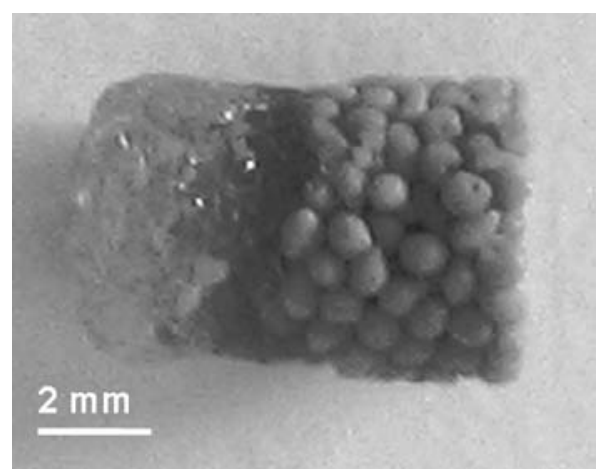

Figure 7 Photograph showing the developed bilayered chitosan scaffolds.

\subsection{Osteochondral bilayered scaffolds}

To create constructs having more favourable integration properties that might be used for osteochondral tissue engineering applications, we have also investigated osteochondral composite porous materials development. Bilayered scaffolds were successfully developed by means of aggregating polymeric and composite chitosan-based particles. Fig. 7 shows the typical scaffolds obtained with this methodology. 

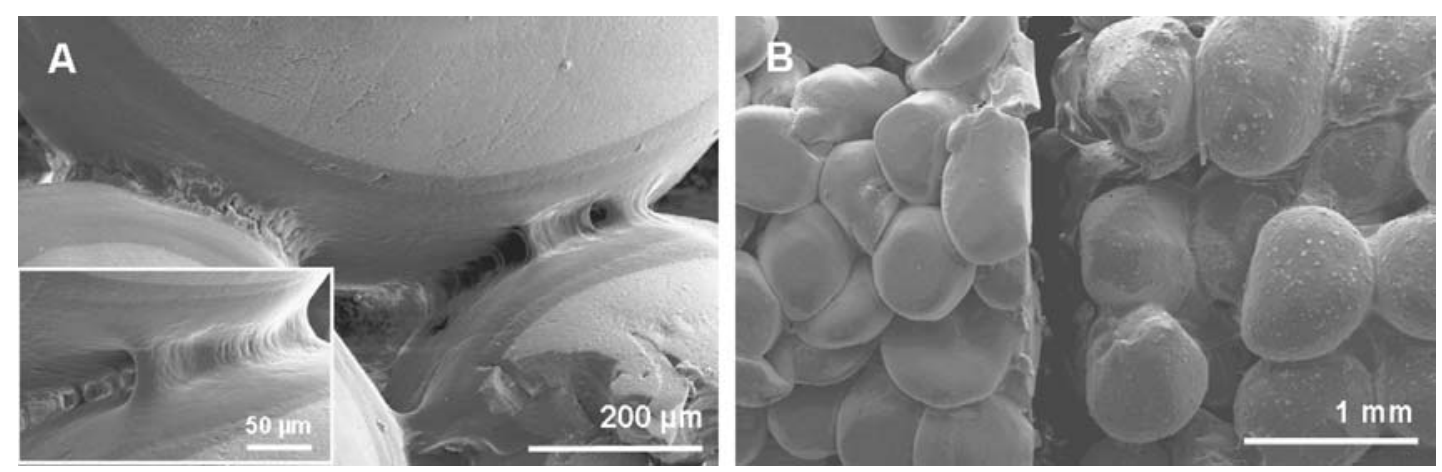

Figure 8 SEM micrographs showing the interface between chitosan particles (A) and scaffolds components (B) obtained using fibrin glue.
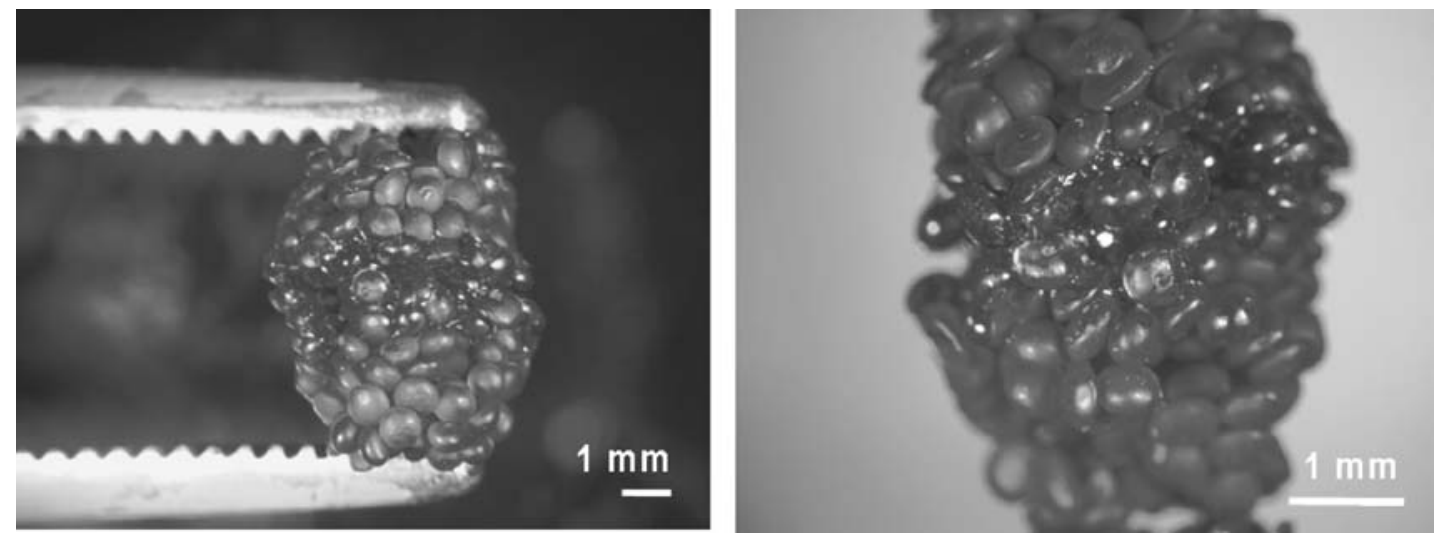

Figure 9 Stereolight photographs showing the interface between both scaffolds components using chitosan glue (brighter area).

Furthermore, the simplest strategy to obtain osteochondral constructs, especially when aiming at minimizing complex co-culture procedures seems to be to culture both components of the scaffolds in their own separated differentiation media and, at a later stage, try to bond the polymeric (cartilage part) and composite (bone part) chitosan-based layers by using e.g. a tissue adhesive. The most widely used tissue sealant is fibrin glue due to its biocompatibility and adhesive properties [40, 41]. Furthermore, this material was already successfully used in the repair of chondral and osteochondral injuries [42]. Studies were carried out using different concentrations of thrombin in order to achieve appropriate viscosity and coagulation time. The adequate thrombin concentration was found to be 4 I.U./ml accomplishing the bonding of both scaffold components in aqueous solution for short immersion periods. The fibrin glue approach has shown to be effective in the bonding of chitosan particles as demonstrated in Fig. 8(A). The bridging created by fibrin allows indeed this particle-linking. Particles exhibit a high compatibility with this sealant. However, for longer immersion periods or after drying, the linkage stability was found to be rather poor leading to the dissociation of both components as shown in Fig. 8(B).

In order to solve this problem, another bonding strategy was followed using a highly viscous chitosan solution as an adhesive layer. As it was already referred, chitosan polymers present very good bioadhesive properties. In fact, with this approach it was possible to accomplish the bonding between both particles and components with additional high material compatibility. By
SEM observation it was not possible to detect the chitosan glue which reveals the high compatibility between the glue and the scaffolds. Stereolight microscopy was used to identify the scaffolds interface when using the chitosan glue. The chitosan glue can be identified by the brighter area in the interface of the scaffolds as shown in Fig. 9. One interesting feature is that this approach does not compromise the scaffolds interconnectivity at the interface, since the bonding sites are still the contact points of adjacent particles where the adhesive is present. This strategy does not create any interface barrier area allowing further cell migration and nutrients flow. One can conclude that a successful adhesion was achieved by means of using a chitosan glue to assemble the polymeric and composite layers in order to fabricate an osteochondral scaffold.

\subsection{Cell seeding and differentiation}

Such tissue engineered constructs may provide an alternative clinical option for the currently used autologous transplantation of mature tissue which is associated with high donor site morbidity. For this purpose, a suitable cell source would likely have to be incorporated into the construct design. First experiments of seeding porous chitosan scaffolds with mesenchymal stem cells isolated from adipose tissue were performed. The preliminary results obtained are very promising as in the seeded scaffolds some events occurred which may indicate an osteogenic and chondrogenic differentiation. In contrast, no events of osteogenic or chondrogenic differentiation in the control wells without 

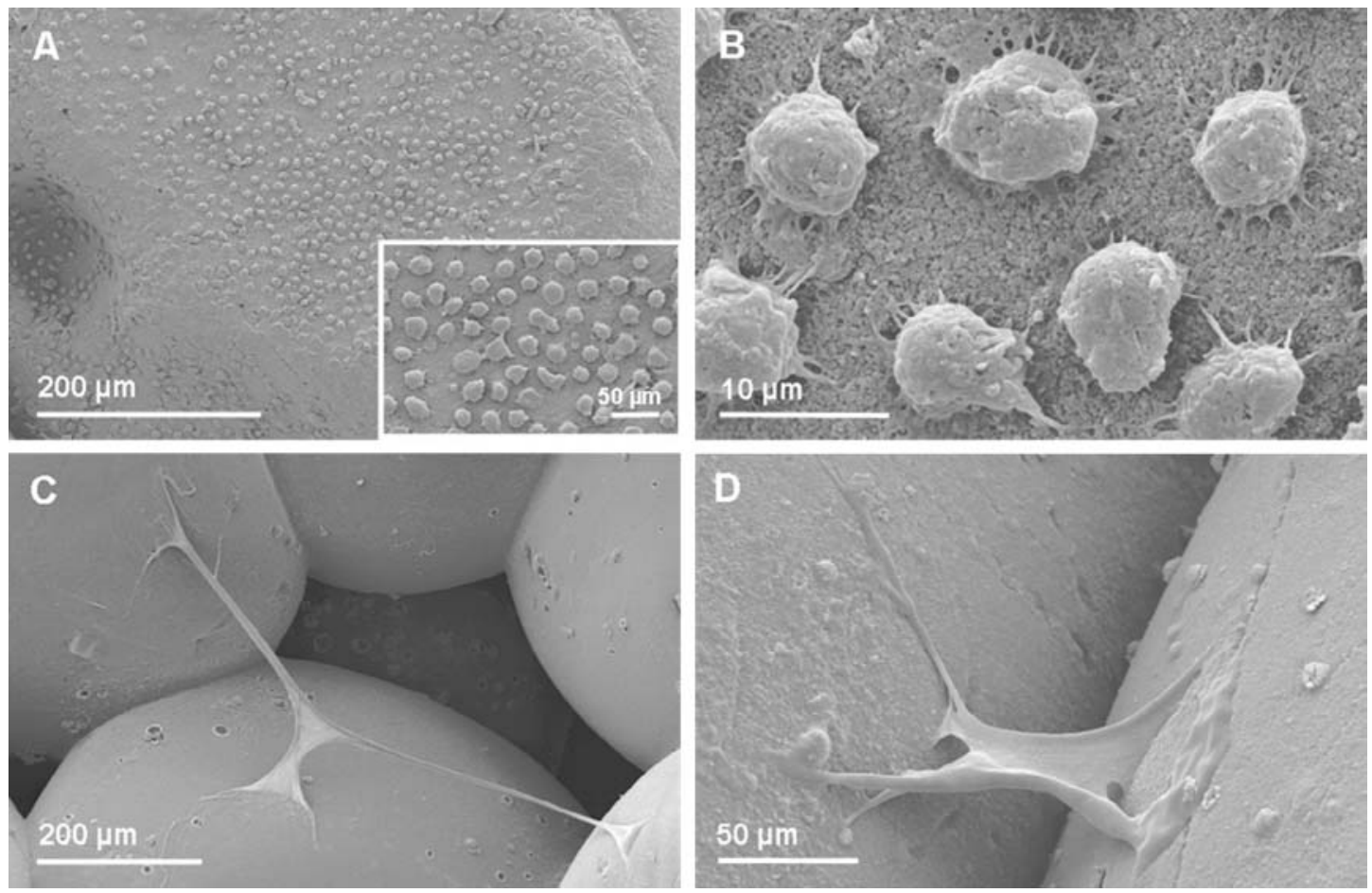

Figure 10 SEM microphotographs showing the morphological difference of cells isolated from adipose tissue, seeded on chitosan particle agglomerated scaffolds and cultured for 2 weeks under chondrogenic (A, B) and osteogenic (C, D) conditions, respectively.

the scaffolds (2D cultures) were detected in this short time frame, as confirmed also by Von Kossa and Alcian Blue staining, respectively. This may propose an influence of the 3D support provided by the scaffolds on the differentiation ability of the cells indicated by a change in cell morphology shown by SEM analysis (Fig. 10). Hence, mesenchymal stem cells isolated from adipose tissue, seeded on the scaffolds and cultured with chondrogenic medium had a rounded shape which is a morphological prerequisite for chondrogenic differentiation (Fig. 10(A) and (B)). The ones cultured with osteogenic medium had a flattened morphology and showed bridging between the chitosan particles which might suggest a differentiation along the osteogenic lineage (Fig. 10(C) and (D)). Similar attachment behaviour has been observed by Borden et al. [13] who seeded primary human osteoblasts in PLAGA-based microspheres sintered scaffolds. The assumption that the cells had in fact differentiated into mature cell types might be corroborated by ALP activity measurements which showed very low levels when cultured in chondrogenic medium (data not shown). On the contrary, scaffolds seeded with cells and incubated in osteogenic medium showed a very high ALP activity compared to the controls cultured without osteogenic supplements. However, future work will focus on the detection of specific markers on the molecular as well as the protein level to confirm these results.

\section{Conclusions}

By means of using a particle aggregation method, it was possible to obtain chitosan-based scaffolds with very promising properties for the use in cartilage and osteochondral applications. $\mu$-CT and MIMICS ${ }^{\circledR}$ could be successfully used for the morphological character- ization of the developed scaffolds. Scaffolds have a mean porosity of $30 \%$ with pores ranging from 100 to $400 \mu \mathrm{m}$ well distributed throughout the scaffolds and clearly interconnected. The developed scaffolds seem to be very adequate for cell ingrowth. In addition, and due to its low pore volume, there is no compromising of the typical mechanical properties of the particle based scaffolds. The developed scaffolds demonstrate no cytotoxicity as evaluated by the MTS assay. Furthermore, very promising osteochondral bilayered scaffolds could also be developed. A simple strategy is also presented based on the use of a material adhesive for obtaining bilayered scaffolds. Preliminary cell seeding and differentiation tests with mesenchymal stem cells isolated from adipose tissue were carried out, indicating cells with osteogenic and chondrogenic morphology in the 3D particle agglomerated scaffolds. Although this needs to be further investigated it is a very promising indicator for the use of the developed scaffolds in the proposed osteochondral applications.

\section{Acknowledgments}

We would like to thank the Portuguese Foundation for Science and Technology for the PhD Grant to Patrícia B. Malafaya (SFRH/BD/11155/2002). This work was partially supported by the European STREP Project HIPPOCRATES (NMP3-CT-2003-505758) and carried out under the scope of the European NoE EXPERTISSUES (NMP3-CT-2004-500283). The authors would also like to acknowledge Materialise (Belgium) for the MIMICS ${ }^{\circledR}$ software provided in the frame of the referred EU projects and Gerald Zanoni from the Ludwig Boltzmann Institute for Experimental and Clinical Traumatology (Austria) for performing the $\mu$-CT scans. 


\section{References}

1. M. E. GOMES, A. S. Ribeiro, P. B. MALAFAYA, R. L. REIS and A. M. CUNHA, Biomaterials 22 (2001) 883.

2. Y. DENG, K. ZHAO, X.-F. ZHANG, P. HU and G.-Q. CHEN, ibid. 23 (2002) 4049.

3. Q. HOU, D. W. GRIJPMA and J. FEIJEN, ibid. 24 (2003) 1937.

4. H. S. YOO, E. A. LEE, J. J. YOON and T. G. PARK, ibid. 26 (2005) 1925.

5. M. NOF and L. D. SHEA, J. Biomed. Mater. Res. 59 (2002) 349.

6. M. E. GOMES, V. I. SiKAVITSAS, E. BEHRAVESH, R. L. REIS and A. G. MIKOS, J. Biomed. Mater. Res. 67A (2003) 87.

7. S. V. MADiHALly and H. W. T. MATtheW, Biomaterials 20 (1999) 1133.

8. P. B. MALAFAYA and R. L. REIS, in "Key Eng Mat" edited by B. Ben-Nissan, D. Sher and W. Walsh (Trans Tech Publications, Zurich 2003) p. 39.

9. S. ZMORA, R. GLICKLIS and S. COHEN, Biomaterials 23 (2002) 4087.

10. K. F. LEONG, C. M. CHEAH and C. K. CHUA, ibid. 24 (2003) 2363.

11. I. ZEIN, D. W. HUTMACHER, K. C. TAN and S. H. TEOH, ibid. 23 (2002) 1169.

12. E. SACHLOS, N. REIS, C. AINSLEY, B. DERBY and J. T. CZERNUSZKA, ibid. 24 (2003) 1487.

13. M. BORDEN, S. F. EL-AMIN, M. ATtAAIA and C. T. LAURENCIN, ibid. 24 (2003) 597.

14. M. BORDEN, M. ATTAWIA and C. T. LAURENCIN, J. Biomed. Mater. Res. 61 (2002) 421.

15. M. BORDEN, M. ATTAWIA, Y. KHAN and C. T. LAURENCIN, Biomaterials 23 (2002) 551.

16. J. E. DEVIN, M. A. ATTAWIA and C. T. LAURENCIN, J. Biomat. Sci. Polym. Ed. 7 (1996) 661.

17. D. H. R. KEMPEN, C. W. KIM, L. LU, W. J. A. DHERT, B. L. CURRIER and M. J. YASZEMSKI, Mater. Sci. Forum. 426-424 (2003) 3151.

18. T. A. HOLlAND, Y. TABATA and A. G. MiKOS, J. Control. Release. 91 (2003) 299.

19. R. G. PAYNE, J. S. MCGONIGLE, M. J. YASZEMSKI, A. W. YASKO and A. G. MIKOS, Biomaterials 23 (2002) 4381.

20. R. G. PAYNE, M. J. YASZEMSKI, A. W. YASKO and A. G. MIKOS, ibid. 23 (2002) 4359.

21. E. L. HEDBERG, A. TANG, R. S. CROWTHER, D. H. CARNEY and A. G. MIKOS, J. Control. Release. 84 (2002) 137.

22. T. M. MEESE, Y. HU, R. W. NOWAK and K. G. MARRA, J. Biomater. Sci. Polym. Ed. 13 (2002) 141.

23. S. E. KIM, J. H. PARK, Y. W. CHO, H. CHUNG, S. Y. JEONG, E. B. LEE and I. C. KWON, J. Control. Release. 91 (2003) 365.
24. A. PERETS, Y. BARUCH, F. WEISBUCH, G. ShOSHANY, G. NEUFELD and S. COHEN, J. Biomed. Mater. Res. 65A (2003) 489.

25. C. T. HUNG, E. G. LIMA, R. L. MAUCK, E. TAKI, M. A. LEROUX, H. H. LU, R. G. STARK, X. E. GUO and G. A. ATESHIAN, J. Biomech. 36 (2003) 1853.

26. J. K. SHERWOOD, S. L. RILEY, R. PALAZZOLO, S. C. BROWN, D. C. MONKHOUSE, M. COATES, L. G. GRIFFITH, L. K. LANDEEN and A. RATCLIFFE, Biomaterials 23 (2002) 4739.

27. P. ANGEle, R. KUJAT, M. NERliCh, J. YOO, V. GOLDBERG and B. JOHNS T ONE, Tissue. Eng. 5 (1999) 545.

28. J. S. TEMENOFF and A. G. MIKOS, Biomaterials 21 (2000) 431.

29. R. K. SANDERS and J. R. CRIM, Seminars in Ultrasound, CT, and MRI 22 (2001) 352.

30. J. A. BUCKWALTER, S. L. WOO, V. M. GOLDBERG, E. C. HADLEY, F. BOOTH, T. R. OEGEMA and D. R. E Y RE, J. Bone and Joint Surg. Am. 10 (1993) 1533.

31. L. HANGODY, P. FECZKO, L. BARTHA, G. BODO and G. KISH, Clin. Orthop. Relat. R (2001) S328.

32. J. GAO, J. E. DENNIS, L. A. SOlCHAGA, V. M. GOLDBERG and A. I. CAPLAN, Tissue Eng. 8 (2002) 827.

33. T. TAGUCHI, Y. SAWABE, H. KOBAYASHI, Y. MORIYOSHI, K. KATAOKA and J. TANAKA, Mater. Sci. Eng. C 24 (2004) 881.

34. J. P. SPALAZZI, K. L. MOFFAT, S. B. DOTY and H. H. LU, in "Proceedings of the Society for Biomaterials 30th Annual Meeting Transactions" (Memphis, 2005) p. 253.

35. J. JIANG, C. T. HUNG, X. E. GUO, G. A. ATESHIAN and H. H. LU, in "Proceedings of the 7th World Biomaterials Congress" (Sydney, 2004) p. 7.

36. R. A. SOUSA, R. L. REIS, A. M. CUNHA and M. J. BEVIS, J. Appl. Polym. Sci. 86 (2002) 2873.

37. P. B. MALAFAYA and R. L. REIS, in "Proceedings of the 7th World Biomaterials Congress" (Sydney, 2004) p. 1285.

38. P. B. MALAFAYA and R. L. REIS, in "Proceedings of 6th International Symposium on Frontiers in Biomedical PolymersFBPS'05" (Granada, 2005) p. O19.

39. P. A. ZUK, M. ZHU, P. ASHJIAN, D. A. DE UGARTE, J. I. HUANG, H. MiZunO, Z. C. Alfonso, J. K. FRASER, P. BENHAIM and M. H. HEDRICK, Mol. Biol. Cell 13 (2002) 4279.

40. L. J. CURRIE, J. R. SHARPE and R. MARTIN, Plast. Reconstr. Surg. 108 (2001) 1713.

41. H. REDL, in "Tissue Glues in Cosmetic Surgery" (Quality Medical Publishing Inc., St. Louis, 2004), p. 27.

42. G. KAPLONYi, I. ZIMMERMAN, A. D. FRENYO, T. FARKAS and G. NEMES, Injury 19 (1988) 267.

Received 7 April

and accepted 20 July 2005 